Acta Technologica Agriculturae 1

Nitra, Slovaca Universitas Agriculturae Nitriae, 2018, pp. 28-32

\title{
PROCESS CONTROL OF PRE-SOWING SEED TREATMENT BY PULSED ELECTRIC FIELD
}

\author{
Galina Petrovna STARODUBTSEVA*, Sergey Alikovich LIVINSKIY, \\ Shaliko Zhoraeyvich GABRIYELYAN, Svetlana Ivanovna LUBAYA, Mihail Anatolevich AFANACEV \\ FGBOU VO Stavropol State Agrarian University, Stavropol, Russia
}

\begin{abstract}
Presented paper investigates the application of a line voltage changer to an installation for pre-sowing seed treatment by pulsed electric field (PEF) in order to increase the sowing quality of seeds and to suppress pathogenic microflora. The installation comprises an AC voltage regulator, a high voltage source, a voltage inverter, a working chamber for seed treatment, a control unit, and current and voltage sensors. The proposed installation differs from the existing apparatuses as it automatically provides the transformation of the pulsed electric field parameters by constant monitoring of power processes in a layer of treated seeds and feedback sending to the control unit. Seed treatment efficiency depends on the dose being determined by the parameters of electric field, namely, intensity in the seed layer, pulse duration, pulse repetition frequency, and seed treatment time. The parameters of rational treatment were determined, and the minimum treatment dose was calculated on the basis of results from the laboratory tests on the effect of pulsed electric field on sowing qualities of winter wheat seeds. It was experimentally confirmed that the proposed installation provides automatic transformation of electric field parameters depending on the changes taking place in the seed layer on the example of seeds with different moisture content maintaining the necessary treatment dose, ensuring the stability and repeatability of results.
\end{abstract}

Keywords: installation; intensity; effect dose; duration and pulse-repetition frequency; sowing qualities of seeds

In order to increase the sowing quality of seeds and to suppress pathogenic microflora, seed pre-sowing treatment by physical factors is performed (Borodin, 1983; Abou El-Yazied et al., 2011; Hainovskiy et al., 2007a, 2017; Rostami Zadeh et al., 2014; Jamshid and Sara, 2017; Xu et al., 2013). Treatment by pulsed electric field (PEF) represents one of the most promising methods for this. Multiple researchers deal with this topic: the pre-sowing treatment of soybean seeds was studied by Hainovskiy et al. (2007b), of carrot seeds by Dulskiy et al. (2009), of onion seeds by Hnukina (2014), of winter wheat by Starodubtseva et al. $(2017 \mathrm{a}, \mathrm{b})$, of haricot beans and corn by Bilalis et al. (2012); Yang et al. (2012) and many others. Increases in the germinating capacity of seeds by up to $12.0 \%$, and in crop capacity by up to $15.0 \%$ were achieved in laboratory and field experiments.

An operator manually regulates the treatment conditions for a given crop according to the results of laboratory experiments. Additional laboratory experiments are required to select treatment conditions for various groups differing in size, the degree of damage, dirtiness, and moisture content; however, these tests are usually not carried out. In consequence, the stability and repeatability of treatment results are not always observed, especially under production conditions.

The principal drawbacks of the studied research are as follows: the absence of monitoring of energy processes occurring in the seed layer treated within the working chamber; absence of a closed-loop control system with feedback from monitored results; absence of automatic regulation of PEF parameters in accordance with the changes in the seed layer. The electrical characteristics of seeds are: layer capacitance, and seed dielectric constant, which are dependent on seed conditions (Nelson et al., 2007; Novák, 2013; Novák and Vitázek, 2014; Vitázek and Veres, 2013).

There is a need for a seed-treatment installation which would enable to produce uniform changes in the seed layer and to adjust such PEF parameters as field intensity in the seed layer, duration and pulse repetition frequency on the basis of changes concurrently taking place in the seed layer, thus maintaining the consistency of treatment dose.

The purpose of this work is to develop and check the voltage changer operation with automatic control of the processes for pre-sowing seed treatment by pulsed electric field.

\section{Material and methods}

Experiments studying the dependence of sowing qualities of winter wheat on the parameters of pulsed electric field were carried out at the accredited laboratory of Stavropol State Agrarian University.

Seed sowing qualities have been studied, namely germination energy, germinating capacity and seedling weight depending on field intensity in the seed layer from 0 to $15.0 \cdot 10^{3} \mathrm{~V} \cdot \mathrm{m}^{-1}$ in increments of $2.5 \cdot 10^{3} \mathrm{~V} \cdot \mathrm{m}^{-1}$, pulse 
duration from $20 \mu$ s to $50 \mu$ s in increments of $10 \mu$ s, and pulse repetition frequency from $600 \mathrm{~Hz}$ to $1600 \mathrm{~Hz}$ in increments of $200 \mathrm{~Hz}$; seed moisture content from $10.0 \%$ to $13.5 \%$.

In order to determine the germination energy and germination capacity, seeds were germinated on a filter bed moistened with distilled water in Petri dishes. This process was performed four times and 50 seeds were subjected to the experiment each time.

Seed moisture content was determined by methods defined by intergovernmental standard.

It is based on the measurement of seed weight (sample $-5.0 \mathrm{~g}$ ) before drying and after drying at $130^{\circ} \mathrm{C}$. The measurement accuracy of this method was determined by the measurement error of the given weight $(0.01 \mathrm{~g})$ and it was $0.28 \%$ on the whole.

The seedling weight was determined when counting seed germination capacity by weighing on the scales VPZ 100S, NPV 0.01-300.0 g.

The frequency, duration, and shape of pulses were measured by the oscilloscope TPZ 2024 (Fig. 2).

Electrical capacitances of the empty working chamber and chamber tightly filled with seeds were automatically measured by means of the digital immittance meter MT 4080A. An admissible measurement error of electrical capacitance is $\pm 0.2 \%$ in the capacitance range of $15.91 \mathrm{nF}-$ $159.1 \mathrm{pF}$, on frequencies in the range of $1-10 \mathrm{kHz}$ (according to the rated engineering data of the instrument).

The dielectric constant of winter wheat seeds was determined by measuring of electric capacitance of the working chamber representing a plane capacitor and was calculated according to Eq. (1) (Hainovskiy and Kozurev, 2011):

$$
\varepsilon=\frac{C_{c}}{C}
$$

where:

$C_{c}$ - electrical capacitance of the working chamber tightly filled with seeds, $\mathrm{pF}$

C - electrical capacitance of the empty working chamber, pF

On the basis of Eq. (1) and errors of direct measurement of capacitance $C_{c}$ and $C$, the indirect error of dielectric constant is $\pm 0.28 \%$.

Voltage applied to the electrodes varied from 0 to $300 \mathrm{~V}$. The distance between the electrodes was $2 \cdot 10^{-2} \mathrm{~m}$ and did not change during the experiment.

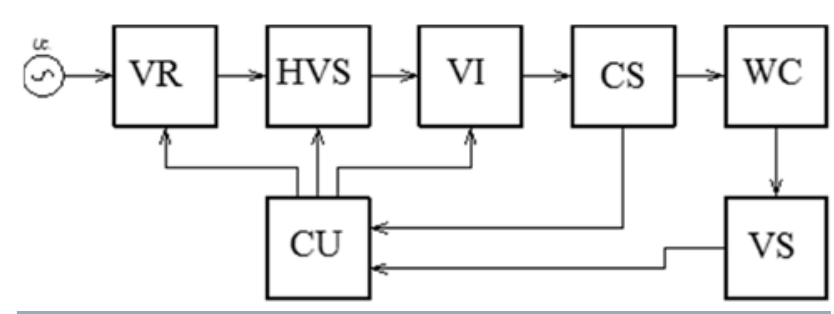

Fig. 1 The structural block diagram of the voltage changer VR - AC voltage regulator; HVS - high voltage source; VI voltage inverter; WC - working chamber; CS - current sensor; VS - voltage sensor; CU - control unit
When seeds were treated by the pulsed electric field, they completely filled the inter-electrode space of the working chamber representing a plane capacitor. In such a manner, the airspace between seeds and electrodes was eliminated and a uniform field effect throughout the layer of the treated seeds was obtained.

The statistical manipulation of research results was carried out by means of the dispersion method.

The object of research is winter wheat seeds of Trio variety, which were harvested in 2016.

Fig. 1 demonstrates the block diagram of the installation with the closed control system operating as follows (Brown, 2007; Livinskiy et al., 2016; Starodubtseva and Livinskiy, 2016).

When the installation is turned on, the $A C$ voltage regulator (VR) is fed with the power source voltage. The regulator performs smooth, stepless regulation and stabilisation of output voltage imposed by the control unit (CU). Moreover, the voltage regulator (VR) eliminates switching intervals in the power supply of the changer, and also switching surge and current rush (Starodubtseva and Livinskiy, 2016).

From the regulator output, alternating voltage is supplied to the high voltage source (HVS), where it is converted into DC voltage with an amplitude effect. The voltage value for the high voltage source (HVS) is set by the control unit (CU). The HVS is a source with pulsed voltage conversion. The HVS output is then fed to the voltage inverter (VI) (Livinskiy et al., 2016).

The voltage inverter ( $\mathrm{VI})$ generates high-voltage pulses from the DC voltage of the HVS coming to the input. The control unit (CU) gives a command to switch on the inverter for a period of each duration pulse.

In such a manner, the developed high voltage pulse for seed treatment gets to the electrodes of the working chamber (WC) through the current sensor (CS). The working chamber (WC) represents two potential plates filled up with the seed layer without an air gap between the seed layer and electrodes, and thus any eventual voltage drop in the air gap is eliminated.

The control unit $(\mathrm{CU})$ receives information related to the processes taking place in the working chamber (WC) during seed treatment from the sensors: the current sensor (CS) provides information on current consumption by the electrodes of the working chamber (WC); the voltage sensor (VS) provides information on the applied voltage value to the electrodes of the working chamber (WC). The obtained data allow the control unit (CU) to calculate the necessary and identical value of effect dose that is to be transmitted to the seed layer.

The already designed and patented software for the voltage changer control can be also set for microcontrollers.

The control unit (CU) adjusts the effect parameters such as voltage pulse value, its duration, and pulse repetition frequency. The value of voltage pulse quantity is transmitted to the high voltage source (HVS) by the control unit (CU). The duration and frequency of pulses are set by the control unit (CU) by means of the inverter (VI). Therefore, the changer contains feedback loops on current consumed by the working chamber (WC), on voltage applied to the electrodes of the working chamber (WC). 


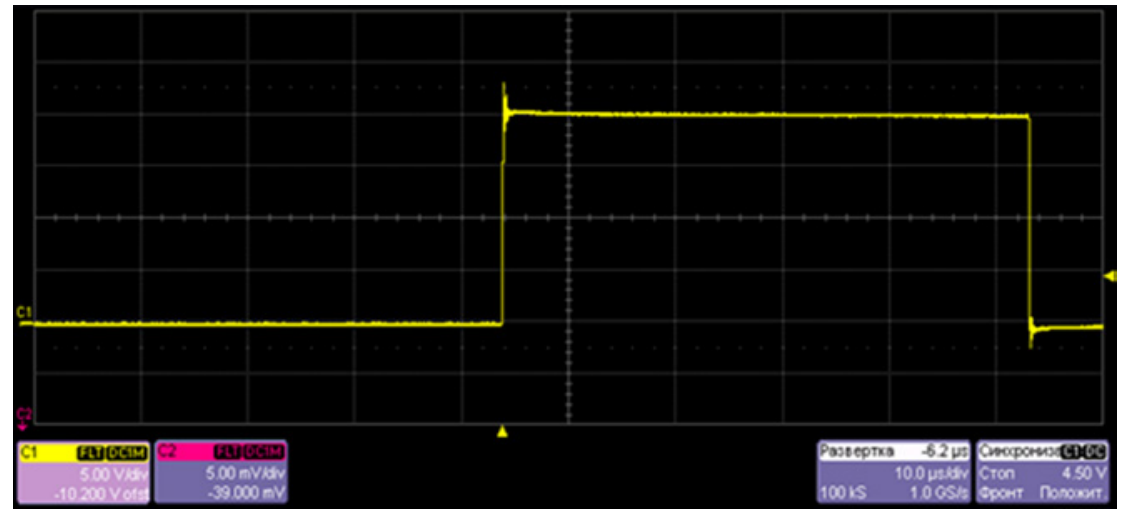

Fig. 2 Oscillogram of voltage pulse on the electrodes of the working chamber $\tau_{\text {imp }}=50 \mu \mathrm{s}, f=600 \mathrm{~Hz}, U=200 \mathrm{~V}$

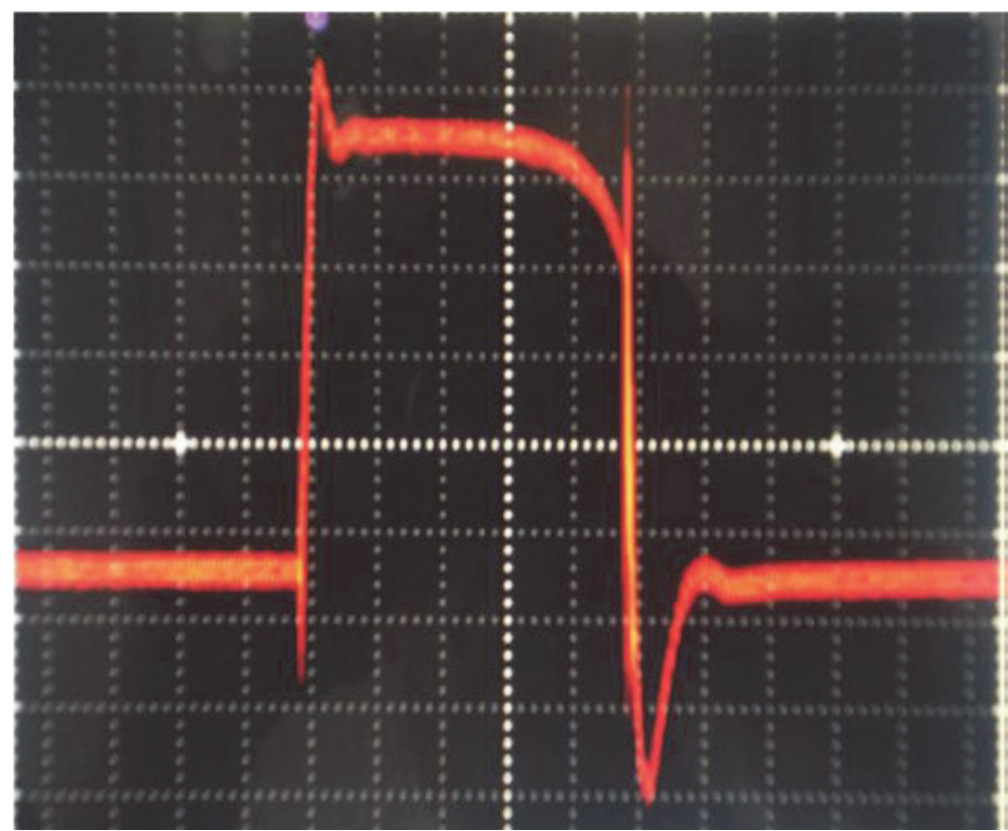

Fig. 3 Oscillogram of voltage pulse on electrodes of the working chamber $\tau_{\text {imp }}=50 \mu \mathrm{s}, f=600 \mathrm{~Hz}, U=200 \mathrm{~V}$

Fig. 2 represents the oscillogram of voltage pulse applied to the electrodes of the working chamber (WC) with a square shape, which simplifies the calculation of PEF effect dose on seed grain.

Fig. 3 represents the oscillogram of voltage pulse of the installation for pre-sowing seed treatment by PEF under parameters identical to the oscillogram in Fig. 2. It is obvious that the pulse of this oscillogram is of a distorted form with a tight edge and section, which makes the calculation of pulse duration and dose in PEF more difficult (Hnukina, 2014).

The results of the conducted laboratory set of experiments on the seed treatment of winter wheat by PEF depending on pulsed electric where:

$D$ - effect dose on seeds by PEF, $\mathrm{V} \cdot \mathrm{s} \cdot \mathrm{m}^{-1}$

E - intensity in seeds layer, $\mathrm{V} \cdot \mathrm{m}^{-1}$

$\tau_{\text {imp }}$ - pulse duration, $\mu \mathrm{s}$

$\tau_{\text {edge }}$ - acceleration time, $\tau_{\text {edge }} \approx 0$, whereas acceleration time is negligibly low for pulses of the given installation, nearly $100 \mu$ s (Fig. 2), and can be excluded from the calculation

$f \quad$ - frequency, $\mathrm{Hz}$

$t_{\text {treat }}$ - treatment time - exposure, $\mathrm{s}$

The value of amplitude effect dose for winter wheat was $2,880 \mathrm{~V} \cdot \mathrm{s} \cdot \mathrm{m}^{-1}$ in the mentioned rational conditions.

\section{Results and discussion}

Table 1 illustrates the results of dependence of seed sowing qualities on their moisture content treated by PEF under rational conditions. Seed moisture content varied from $10.0 \%$ to $13.5 \%$.

As can be seen from the results represented in Table 1, the increase in moisture content of the seeds untreated by PEF by $0.5-2.5 \%$ has led to an increase in their germination energy by $3.7-7.6 \%$, germinating capacity by $0.4-1 \%$, and seedling weight by $21.0 \%$ in comparison with the seeds with a $10 \%$ initial moisture content. For seeds treated by $\mathrm{PEF}$, there was an increase in germination energy by $30.5-33.5 \%$, germinating capacity by $1.1-2.2 \%$, seedling weight by $22.5-25.5 \%$ in comparison to the seeds untreated by PEF. The determination accuracy of germination energy was $1.9 \%$, germinating capacity $1.0 \%$, and seedling weight $1.5 \%$.

Table 2 illustrates the data on the feedback system check of the installation for pre-sowing seed treatment on an example of seeds with different moisture content. The capacitance of the seed layer, frequency and pulse duration were measured for each moisture content value. Dielectric constant and effect dose were calculated.

The analysis of the experimental results demonstrates that the values of capacitance and dielectric constant of the seed layer increase with an increase in moisture content. 
Table 1 Sowing qualities of winter wheat seeds of Trio variety of different moisture content treated under rational conditions

\begin{tabular}{|c|c|c|c|c|c|c|c|}
\hline \multirow{2}{*}{$\begin{array}{l}\text { Value of moisture } \\
\text { content in } \%\end{array}$} & \multirow{2}{*}{ Variant } & \multicolumn{2}{|c|}{ Germination energy } & \multicolumn{2}{|c|}{ Germinating capacity } & \multicolumn{2}{|c|}{ Seedling weight } \\
\hline & & $\%$ & $\%$ control sample & $\%$ & $\%$ control sample & kg $10^{-5}$ & $\%$ control sample \\
\hline \multirow{2}{*}{10.0} & $\begin{array}{c}\text { untreated } \\
\text { (control sample) }\end{array}$ & 61.5 & 100.0 & 96.7 & 100.0 & 2.86 & 100.0 \\
\hline & treated & 82.1 & 133.5 & 98.8 & 102.2 & 3.58 & 125.2 \\
\hline \multirow{2}{*}{10.5} & $\begin{array}{c}\text { untreated } \\
\text { (control sample) }\end{array}$ & 65.2 & 100.0 & 97.1 & 100.0 & 3.36 & 100.0 \\
\hline & treated & 86.3 & 132.4 & 99.1 & 102.1 & 4.20 & 125.0 \\
\hline \multirow[t]{2}{*}{11.5} & $\begin{array}{c}\text { untreated } \\
\text { (control sample) }\end{array}$ & 68.6 & 100.0 & 97.7 & 100.0 & 3.42 & 100.0 \\
\hline & treated & 89.9 & 131.0 & 99.2 & 102.3 & 4.28 & 125.1 \\
\hline \multirow[t]{2}{*}{12.5} & $\begin{array}{c}\text { untreated } \\
\text { (control sample) }\end{array}$ & 69.0 & 100.0 & 97.8 & 100.0 & 3.46 & 100.0 \\
\hline & treated & 90.1 & 130.2 & 98.9 & 101.1 & 4.24 & 122.5 \\
\hline \multirow[t]{3}{*}{13.5} & $\begin{array}{c}\text { untreated } \\
\text { (control sample) }\end{array}$ & 69.1 & 100.0 & 97.5 & 100.0 & 3.44 & 100.0 \\
\hline & treated & 90.2 & 130.5 & 99.2 & 101.7 & 4.26 & 123.8 \\
\hline & $S_{x}$ in $\%$ & 1.9 & - & 1.0 & - & 1.5 & - \\
\hline
\end{tabular}

Table 2 Dependence of PEF parameters on the electrical characteristics of seeds with different moisture content

\begin{tabular}{|c|c|c|c|c|c|}
\hline Moisture in \% & $\begin{array}{c}\text { Layer capacitance } \\
\boldsymbol{C}_{\Sigma} \text { in } \mathrm{pF}\end{array}$ & $\begin{array}{l}\text { Layer dielectric } \\
\text { constant } \varepsilon_{\text {layer }}\end{array}$ & $\begin{array}{l}\text { Pulse-repetition } \\
\text { frequency } f \text { in } \mathrm{Hz}\end{array}$ & $\begin{array}{l}\text { Pulse duration } \tau_{\text {imp }} \\
\text { in } \mu \mathrm{s}\end{array}$ & $\begin{array}{c}\text { Effect dose } D \\
\text { in V.s. } \mathrm{m}^{-1}\end{array}$ \\
\hline 10.0 & 214.7 & 4.63 & $1,200.0$ & 40.0 & $2,880.0$ \\
\hline 10.5 & 227.9 & 4.94 & $1,152.7$ & 41.7 & $2,884.0$ \\
\hline 11.5 & 251.3 & 5.41 & $1,107.4$ & 43.3 & $2,877.0$ \\
\hline 12.5 & 268.5 & 5.79 & $1,069.8$ & 44.9 & $2,882.0$ \\
\hline 13.5 & 284.9 & 6.17 & $1,020.9$ & 47.0 & $2,879.0$ \\
\hline
\end{tabular}

Capacitance ranges from $214.7 \mathrm{pF}$ to $284.0 \mathrm{pF}$, dielectric constant from 4.63 to 6.17 . The identical results for other biological materials were presented by other authors (Nelson et al., 2007; Novák, 2013; Novák and Vitázek, 2014) and thus it can be concluded that dielectric constant and loss tangent increased with an increase in material moisture content.

There was immediate automatic change in pulsed electrical field parameters with alternations in electrical characteristics of the seed layer. The pulse-repetition frequency ranged from $1,200.0 \mathrm{~Hz}$ to $1,020.9 \mathrm{~Hz}$, and pulse duration increased from $40.0 \mu \mathrm{s}$ to $47.0 \mu \mathrm{s}$. The installation maintaining the required amplitude effect dose from $2,877.0 \mathrm{~V} \cdot \mathrm{s} \cdot \mathrm{m}^{-1}$ to $2,884.0 \mathrm{~V} \cdot \mathrm{s} \cdot \mathrm{m}^{-1}$ (changes within $\pm 2 \%$ ) provides the stability of seed treatment, as confirmed by the data related to their sowing qualities (Table 1).

\section{Conclusions}

The following can be concluded:

1. Experimentally verified control system of the voltage changer with feedback from the current and voltage sensors in the working chamber allows maintaining the constant effect dose on the seed grain, regardless of changes in electrical ratings of a seed layer for account of changes of duration and pulse repletion frequency (PRF).

2. The treatment of winter wheat seeds under rational conditions allows increasing of germination energy up to $32.41 \%$, germination capacity up to $3.2 \%$, seedling weight up to $23.8 \%$ in relation to the seeds of the control variants.

\section{References}

ABOU EL-YAZIED, A. - SHALABY, O. A. - EL-GIZAWY, A. M. - KHALF, S. M. - El-SATAR, A. 2011. Effect of magnetic field on seed germination and transplant growth of tomato. In Journal of American Science, vol. 7, no. 12, pp. 306-312.

BILALIS, D. J. - KATSENIOS, N. - EFTHIMIADOU, A. - KARKANIS, A. 2012. Pulsed electromagnetic field: An organic compatible method to promote plant growth and yield in two corn types. In Electromagnetic Biology and Medicine, vol. 31, no. 4, pp. 333-343. BORODIN, I. F. 1983. Development of electro-technology in farm production. In Mechanization and Electrification of Agriculture, no. 6, pp. 27-31.

BROWN, M. 2007. Diet Source. Calculation and Construction. K: MK-Press, 288 pp. 
DULSKIY, A. V. - STARODUBTSEVA, G. P. - HAINOVSKIY, V. I. 2009. Presowing seed treatment of carrot varieties with vitamin- 6 by pulsed electric field. In Bulletin of the Russian Agricultural Science, no. 6, pp. 59-60.

HAINOVSKIY, V. I. - KOZUREV, A. E. 2011. Development of dielectric constant of crop seeds. In Mechanization and Electrification of Agriculture, no. 11, pp. 30-31.

HAINOVSKIY, V. I. - KOPULOVA, O. S. - KOZUREV, A. E. 2012. Effect of doze calculation of pulsed electric field on seeds. In Agrarian Russia, no. 9, pp. 37-42.

HAINOVSKIY, V. I. - LUBAYA, S. I. - KOPULOVA, O. S. - AFANASEV, M. A. 2017. The method of pre-sowing seed treatment. In Machine Operator, no. 1, pp. 14-15.

HAINOVSKIY, V. I. - STARODUBTSEVA, G. P. - RUBTSOVA, E. I. HACHENKO, A. A. 2007a. The method of pre-sowing treatment of soybean seeds by electric field. Patent for invention RUS 2340139, April 022007.

HAINOVSKIY, V. I. - STARODUBTSEVA, G. P. - RUBTSOVA, E. I. 2007b. Pre-sowing stimulation of seeds of soybean pulsed electric field. In Mechanization and Electrification of Agriculture, no. 10, pp. 17-18. HNUKINA, A. G. 2014. The rationale of the electro-technological parameters and modes of the low-voltage activator for pre-sowing treatment of onion seeds. Dissertation, Stavropol, 169 pp.

JAMSHID, R. - SARA, A. 2017 Influence of magnetopriming on germination, growth, physiology, oil and essential contents of cumin (Cuminum cyminum L.). In Electromagnetic Biology and Medicine, vol. 36, no. 4, pp. 325-329.

LIVINSKIY, S. A. - STARODUBTSEVA, G. P. - AFANASEV, M. A. 2016 Voltage transformer for the installation of pre-sowing seed treatment. In APK Stavropolie, Bulletin, no. 4, pp. 35-39.

NELSON, S. O. - GUO, W. - TRABELSI, S. - KAY, S. J. 2007. Dielectric spectroscope of watermelons for sensing quality. In Measurement Science and Technology, vol.18, pp. 1887-1892.
NOVÁK, J. - VITÁZEK, I. 2014. Electrical properties of sunflower achenes. In Acta Technologica Agriculturae, no. 4, pp. 109-113.

NOVÁK, J. 2013. Electrical properties of popcorn grains. In Acta Technologica Agriculturae, no. 2, pp. 43-46.

ROSTAMI ZADEH, E. - MAJD, A. - ARBABIAN, S. 2014. Effects of electromagnetic fields on seed germination in Urtica dioica $\mathrm{L}$. In International Journal of Scientific \& Technology Research, vol. 3, no. 4, pp. 365-368.

STARODUBTSEVA, G. P. - LIVINSKIY, S. A. 2016. AC voltage regulator. In Machine Operator, no. 1, pp. 46- 47.

STARODUBTSEVA, G. P. - LIVINSKIY, S. A. - LUBAYA, S. I. - KUSMONOV, V. I. 2017a. The effect of the pulsed electric field (PEF) on sowing qualities of seeds depending on their moisture content and damage degree. In Central Scientific Bulletin, no. 8, vol. 25, pp. 74-76.

STARODUBTSEVA, G. P. - LIVINSKIY, S. A. - LUBAYA, S. I. - AFANASEV M. A. 2017b. The rationale for modes of pre-sowing seed treatment of winter wheat by pulsed electric field (PEF). In Central Scientific Bulletin, vol. 25, no. 8, pp. 76- 79.

VITÁZEK, I. - VERES, P. 2013. Drying rate of grain maize. In Acta Technologica Agriculturae, vol. 16, no. 2, pp. 31-33.

YANG, Y. - XI, G. - ZHANG, S. - LIU, K. - ZHANG, X. 2012. Development and application of pulsed electric field instrument with extremely low frequency and high-voltage for biological effects. In Transactions of the Chinese Society of Agricultural Engineering, vol. 28, no. 2, pp. 49-54.

XU, J. - TAN, M. - ZHANG, S. - LI, F. 2013. Improving paddy seed vigor by corona discharge field processing and dielectric separation. In Transactions of the Chinese Society of Agricultural Engineering, vol. 29 , no. 23 , pp. 233-240. 